\title{
Competitive Gains in the Local Productive Arrangement Saffron Mara Rosa
}

\author{
Ernane Rosa Martins ${ }^{1}$, Solange da Silva ${ }^{2}$, Silvio de Jesus Batista ${ }^{2}$ \\ ${ }^{1}$ Coordination of Information Technology Area, Federal Institute of Education Science and Technology Goias, Luziânia, Brazil \\ ${ }^{2}$ Department of Industrial and Systems Engineering, University of Goiás, Goiânia, Brazil
}

\section{Email address:}

ernane.martins@ifg.edu.br (E. R. Martins), solansilva.ucg@gmail.com (S. da Silva), sucessosbarra@hotmail.com (S. de J. Batista)

\section{To cite this article:}

Ernane Rosa Martins, Solange da Silva, Silvio de Jesus Batista. Competitive Gains in the Local Productive Arrangement Saffron Mara Rosa. International Journal of Economic Behavior and Organization. Vol. 3, No. 6, 2015, pp. 97-102. doi: 10.11648/j.ijebo.20150306.14

\begin{abstract}
This work deals with the resulting cooperation of the Local Productive Arrangement gains (LPA) Saffron Mara Rosa. This research aims to identify the competitive gains of the LPA Saffron Mara Rosa. The methodology of the proposed study is theoretical, / literature, practical / case study and qualitative exploratory. As a result the Mara Rosa Saffron LPA has submitted the following competitive gains: economies of scale and market power (market forces and trade relations); Provisions solutions (shared marketing, training and credibility assurance); learning and innovation (collectively and industry spread); the reduction of costs and risks (productivity and shared activities); social relationships (family ties). It was concluded that the LPA researched shows satisfactory results despite the distance between the entities involved and accompanying policies.
\end{abstract}

Keywords: Local Clusters, Competitive Gains, Corporate Earnings

\section{Introduction}

The twentieth century was marked by various economic factors, generating changes in the relations between organizations / companies, associates and customers. The factors that stood out were the technological changes, institutions and relationships among its members, who now have important role in their development.

Production systems have undergone enormous transformations. In contrast, there is a need on the part of businesses, upgrading, involving all its production process. LPAs involve all actors with strong relationships in pursuit of common goals in order to ensure the quality of life of all who are part of the chain.

According to Araújo (2014), the prospect is that the clusters could contribute to the improvement of the indicators of income, employment and quality of life. In addition, they can provide better regional development level to a territory [1].

This research aims to identify the competitive gains of the LPA Saffron Mara Rosa.

The methodology of the proposed study is theoretical, / literature, practical / case study and qualitative exploratory.

This research is justified by the limited literature on the results of the LPAs cooperation gains in the State of Goiás.

So based on the above, this article is divided into five sections, in this present section presents besides the introduction, the definition of the research problem, the goal, the rationale and importance of the study and structure of this research. Section 2 presents the theoretical framework, with the formation of a conceptual and theoretical base, providing subsidies for the development of this study. Section 3 presents the method used and the technical and methodological procedures used for the study. Section 4 presents the analysis and discussion of the results obtained in the research. Finally, in section 5 shows the relationships identified between the constructs used and the cases studied in the research.

\section{Literature Review}

Cassiolato and Lastres (2003, p 27) define clusters as territorial agglomerations of economic, political and social agents focusing on a specific set of economic activities that have the same ties that incipient. Usually involve the participation and interaction of companies. And also include several other public and private institutions for: training of human resources (such as schools and universities); research, development and engineering; policy, promotion and funding [2].

In LPA approach, there are some advantages which are 
highlighted by Cassiolato and Lastres (2003), such as [2]:

It shows an analysis unit that differs from the traditional, based at the company, sector, establishing a connection between the territory and the economic activities that are part of clusters;

Brings your attention to groups of economic agents and related activities, with innovative and productive characterization;

Scrutinizes the space where learning takes place, which are created productive and innovative capabilities which arise tacit knowledge;

It is the level at which the learning promotion policies, innovation and creation of training can be defined, ie effective.

On the other hand, Campos (2004, p 58) highlights the importance of integration and cooperation in its definition of LPA: Integration or organization of a group of small and medium-sized firms and / or the presence of cooperation related to the core business of a group of companies. The interaction or cooperation may extend to the educational institutions, trade associations, unions, competitors, suppliers, customers and also to the government. [3]

This integration makes the various companies that make up the clusters start to interact with the institutions and partners to develop partnerships, alliances, innovation and knowledge. Brito and Albagli (2003) define clusters as territorial agglomerations of economic agents, political and social, with axis in a characteristic set of economic activities and presenting synergy, connectivity and interdependence. [4]

According to Costa (2010, p. 128), Productive agglomerations shall be construed as heterogeneous learning organizations, innovate and evolve, and where external knowledge and information flows are of fundamental importance in "cross-fertilization" of agents; the spillovers of knowledge, that leverage the locale a positive synergistic effect; and in the midst of the relationship and interdependence between companies and those with other local institutions responsible for research, development and dissemination of technological knowledge [5].

In the opinion of the author, the agglomeration is all of the following companies around a common activity, with the same pre-disposition to cooperate with each other.

In the structure of governance, Araújo (2014, p. 56) points out that clusters can take many forms in its governance structure in a network of companies. Thus, there is no magic formula or a single recipe. The ideal way depend on the size of the companies comprising the arrangement or local productive system, its production characteristics, culture, feeling of belonging of the members, the type of product, division of labor and interdependence between the companies [1].

According to the author, there are several factors that should be analyzed so that the formation of this structure reaches its success, with representative political, economic and social, that have the acceptance of the whole agglomeration, in building a cluster focused on the representation of its members.

To Balestrin and Verschoore (2008), there are five competitive gains that facilitate the understanding of the results of cooperation networks, arising from the relationship that members may have. They are: greater scale and market power; generation of collective solutions; reducing costs and risks; accumulation of capital; knowledge and collective learning and innovation [6].

Knowledge sharing is one of the first benefits widely recognized by network relations. So when companies collaborate to develop a technology, the resulting knowledge will be available to all partners. Each partner can then aggregate and potentially receive a larger amount of knowledge concerning same investment made individually [6].

The main alternative way to solving problems faced by exporting SMEs on international competitiveness is the formation of groups that enhance the productive capacity and reduce promotion and production costs. The idea of working in associative bases enables companies to hit the market in a sustainable, competitive and sustainable manner.

For a network constitutes in an effective learning environment and thus fosters innovation in associates is necessary to highlight some enablers conditions, namely: trust relationships between entrepreneurs, decentralized and less hierarchical structure, informal communication, the existence of spaces and moments that make possible the socialization of knowledge and access to new knowledge and external expertise [6].

According to Santos, Diniz and Barbosa (2004, p. 38), although they may not be sufficient or necessary conditions, the main factors in clusters and regional economy that can be highlighted as very important or factors able to leverage the development of LPAs are as follows [7]:

Administrative Headquarters of the companies are in LPA;

A significant part of financing decisions to be investment in LPA (with equity or third party);

Do not belong to peripheral industrial systems;

Properties of brand and product technologies are mainly companies whose headquarters are in LPA;

Development of specialized machines and supplies be held at LPA;

Product development is carried out in LPA;

Institutionalized cooperation providing basic services;

Sensitivity government entities to the LPA entities needs and close cooperation between these entities and the representative of the companies;

Presence of technological development institutions in LPA;

Permanent and participatory strategic planning in LPA;

Access to skilled labor trained for creative and strategic activities of the sector;

Degree of trust existing on site.

All items described by the authors represent the development and structuring of clusters, enabling greater security, cooperation, planning, innovation, learning and advancement in technology to members. 
The competitive gains related to scale and market power gains highlight that the greater the number of companies, the greater the ability to obtain economies of scale and market power. This represents greater bargaining power with suppliers, market power and, again according to (BALESTRIN and Verschoore, 2008), enables higher gain trading in their relations and trade agreements and increase representativeness and credibility [6].

Competitive earnings related to collective solutions relate to the services, knowledge, technology, products and infrastructure provided by the network to associate in order to generate mutual gains to all participants, ensuring support for greater breadth shares (BALESTRIN and Verschoore, 2008). Finally, it points out that the maintenance of these collective actions can lead to strengthen their ties and closer ties to members of the network [6].

The Inter-organizational knowledge, the one created by the interaction between organizations, constitutes one of the broadest dimensions of knowledge generation. This process begins at the individual level and through the interaction between tacit and explicit knowledge between individuals, groups and organizations, is now a more complete level of knowledge, deep and meaningful. To be effective, a synergy and stimulating environment it is necessary in which the experiences, feelings and mental images are shared [6].

The gains related to the accumulation of social capital are due to the deepening of relations between individuals and to increase the feeling of belonging and the development of group relations other than those purely economic. As a result, it appears to be parallel to benefit opportunism limitation. Because there are several reasons for companies to cooperate there are significant incentives for the development of opportunistic actions by the involved [6].

\section{Research Methodology}

The methodology of work is theoretical / bibliographic nature, practice / case study and qualitative exploratory.

Minayo (2010, p. 57) says qualitative approaches best meet the research groups, relations and document analysis [8] Moreover, such an approach seeks precision, avoiding waste in data analysis. Qualitative research focuses on the study object processes [9].

Semi-structured interviews were conducted with the aim of researching the results of the LPA cooperation gains.

Respondents were selected in the LPA-site visit, being chosen members who were active within the LPA searched.

The questionnaire was adapted from the questionnaire developed by researchers at the Universidade do Vale do Rio dos Sinos (UNISINOS) and used in the Project PRC / CER agreement $001 / 2012$, with the permission of the authors.

Interviews in LPA were previously scheduled and carried out in 2014, through site visits, which were recorded with the permission of the members.

The LPA respondents are shown in Table 1, and are identified with the letter $\mathrm{E}$.
Table 1. Interviewed.

\begin{tabular}{ll}
\hline Code & Function \\
\hline E1 & President \\
E2 & Associate \\
E3 & Associate \\
\hline
\end{tabular}

It was used content analysis to analyze strategy of research data.

\section{Analysis and Discussion of the Results}

LPA is a Cooperative of Saffron Producers (COOPER SAFFRON) from the town of Mara Rosa. According to his manager in 2014 it had 70 members, but only 30 active. The processing unit of production had five (5) employees. Some time ago they were around thirty (30) employees.

\subsection{Presentation and Historical Context}

In 1986, the Federal University of Goiás (UFG) / CNPq and AGENCY RURAL already developed work studies the production of saffron chain and local production system, according to the RG-LPA (2007) [10].

Castro et al. (2010) points out that the LPA is very specific and rich. Castro also highlights that were developed various $\mathrm{R} \& \mathrm{D}$ projects that were generated several research papers and publications in journal articles. In the same period, they were produced and / or adapted by UFG equipment such as slicer, oven, polisher, burnisher, greenhouse and industrial dryer, which contributed to technological development of actors in the LPA, ie associates [11].

At the beginning of 2001, SIC was visited by the mayor and municipal entities, requesting support for the implementation of a saffron processing industry. That same year, was set up a working group for the achievement of the project, formed by Sectec, Goiana Agency for Regional Development (AGDR), Ministry of Agriculture, Livestock and Irrigation (SEAGRO), Secretary of State for Management and Planning (SEGPLAN ), Agency Goiana of Transport and Works (AGETOP), SEBRAE, Ministry of Agriculture and Food Supply (MAPA), the Bank of Brazil, the Catholic University of Goiás (UCG) and Ministry of National Integration (MIN) (RG-LPA 2007) [10].

In early 2002, the Intermunicipal Consortium of Middle North Goiano Development was created, through the Ministry of Agrarian Development (MDA) and National Program of Family Agriculture Development (PRONAF), in order to establish vertical integration between the municipalities in the region (RG-LPA, 2007) [10].

On June 24, 2003, it was created the Cooperative of Saffron Producers (COOPERAÇAFRÃO).

In May 2007, an elaboration of the development plan process was created, through strategic planning, aiming to encourage and support actions of social and economic development through clusters methodology. This plan took into account the local situation and the regional context, among which are:

The capital increase, favoring the economic and 
environmental sustainability;

Internalize concepts and planning practices, focusing on enhancement of local identity;

Promote the integration of policies, programs, projects and development initiatives, seeking partnerships and strategic alliances between public and private institutions for the development and strengthening of LPA and region (RG-LPA in 2007, p.7) [10].

As RG-LPA (2007), the LPA in 2003, had the participation of 23 members, who constituted the COOPERAÇAFRÃO. In 2006, it built the processing unit and commercialization of saffron, which was considered an increase in the maturity and credibility of the associates, whose group had 63 cooperative [10].

\subsection{Respondents' Answers}

Among the respondents' answers, the most indicative were chosen according to the objectives of this research, avoiding repetitions.

After analyzing the interviews said LPA, as the benefit learning and innovation, it was revealed that in this regard there has been some disagreement in the responses of members The speech of E2 and E3 interview shows that there was no innovation, mainly on the extraction of raw matter in the soil, which has hampered the harvest of saffron and caused injury to members. On the other hand, the respondent E1 said there was innovation in LPA, highlighting advances in industrialization of the product via COOPERAÇAFRÃO, who went on to industrialize the product.

It was reported by the respondent associated:

"In Mara Rosa region and the changes are very slow without significant technological innovations that can contribute to increase the volume of saffron production" (E2).

On the issue of innovation, the results of the analysis showed the unfavorable environment for innovation on the part of members, mainly in the extraction of raw materials.

Furthermore, it is emphasized that:

"The more involved you are associated, the more relevant it becomes this benefit and vice versa" (E1).

As for the reduction of costs and risks, the benefits provided represent the shared activities, confidence in new investments, transactional ease and productivity as described Balestrin and Verschoore (2008) [6].

They were reported by members interviewed:

"Actually cooperated only win being cooperative, if only because we need to lower costs and improve quality" (E1).

"There was no reduction of costs, but improved financing and credit by Cooperativa" (E3).

One of the risks highlighted in the LPA is the time of harvest, in which the product is its low price and expensive labor to extract the product in the field. In this regard, there is little growth in the expansion of sales and profitability This is due mainly to lack of resources and lease of land, which has become costly.

The cost reduction benefit and risks seeks to share all shares between the participants in order to share the results they achieved. Thus, it can highlight access to non-existent resources by the producer, such as financing and new lines of credit from members of LPA, improving the relationship itself between the members. This was pointed out by E2 interviewed as very important benefit for the associated, since:

"Is the result of all that was planned at the beginning of the year brings hope for improvement in the production of saffron for all members" (E2).

Resulting in increased productivity.

As for access to solutions in the category infrastructure and specialized services to increase competitiveness, there is some discontent among the associates, who claim the lack of infrastructure for the flow of the crop for the product storage and inadequate machinery from harvest to the time of drying.

It was reported that:

"There was no improvement in the process, as the service of planting and harvesting of saffron is all manual, each with its own way" (E3).

There was improvement in access to credit and exploration opportunities.

Regarding the infrastructure factor:

"Not made progress as members needed" (E1).

"This is mainly due to the neglect of the old management team that ran the LPA" (E1).

"There was rather an improvement in the image of LPA, by people outside the regional, especially after they put a plate on the LPA, unlike in the region, people, community, market and business people do not value and not give credence and confidence to business "(E3).

As for economies of scale and bargaining power, the results collected as a result of the cooperation of LPAs gains showed an increase in trade relations, credibility and market strength.

A significant improvement was observed in LPA on relations with associates. It can be said that the benefits arising from the trading conditions involving the LPA gains obtained cooperation with suppliers.

"The role of the middleman that once caused a mismatch in the negotiations, by price range, this is a problem solved with the management of LPA" (E1).

Also noteworthy is the no added value in the price of the end product saffron due to foreign competition and the price of land lease with the farmers.

Member companies can expand their market, trade, its credibility and legitimacy.

"The demands appearing, it has to be faster to provide services. For example, companies in São Paulo do not negotiate with producer, but now "(E1).

"There was an increase in sales, but does not add value to the product due to Indian competition" (E3).

As social relations, the majority of respondents believed that there was no improvement. They claim they are too far apart.

"I am kind of suspicious of the system" (E2).

Lack of motivation, confidence in the planting and harvesting saffron reinforces distrust highlighted by the interviewee.

It was observed that the results indicate certain distance 
between the associates and the LPA management. This is justified by the high amounts of inactive members around $55 \%$.

On the issue of social relations, most respondents said that there was no improvement, emphasizes that lack confidence in planting and saffron harvest, ie in business.

"They are kind of suspicious of the system, are distant from each other without communication" (E3).

The study of LPA it was established that the arrangement suffers from the neglect of public actions every public administration. This has caused a gap between the arrangement and governments. Another highlight is the fact that technological innovation is much lower than expected in the cultivation and harvesting, causing the lack of labor qualification for the extraction of raw materials and generating a huge motivation on the part of members.

\subsection{Analysis of Results}

According to the competitive gains cited by the authors Balestrin and Verschoore (2008), were identified in the case study the following results, shown in Table 2 [6].

Table 2. Results obtained in the case study.

\begin{tabular}{ll}
\hline Increased market power & $\begin{array}{l}\text { The increased market power has been } \\
\text { identified in market forces and trade } \\
\text { relations. } \\
\text { The generation of collective solutions was } \\
\text { evident in the shared marketing presented in } \\
\text { conducting training and credibility assurance; } \\
\text { Generation of collective } \\
\text { solutions }\end{array}$ \\
$\begin{array}{ll}\text { Reducing costs and risks } \\
\text { productivity and shared activities. }\end{array}$ \\
$\begin{array}{l}\text { Accumulation of social } \\
\text { capital }\end{array}$ & $\begin{array}{l}\text { The accumulation of capital has been verified } \\
\text { through the presented family ties }\end{array}$ \\
Coletiva collective & $\begin{array}{l}\text { The collective learning was evidenced in } \\
\text { learning }\end{array}$
\end{tabular}

The lack of public encouragement, especially by the municipality, lack of space for drying and storage, obsolete machinery and weak to meet the demand, are some of the problems faced by LPA to improve the performance of associates, mainly for the extraction of raw materials.

According to Balestrim and Verschoore (2008, p.6), "compared to the practices of CERs, the development of collective innovation strategies presents advantage of allowing rapid access to new technologies through its channels of information" [6].

Baking product is still performed by the farmer in the field, in precarious situations, to reduce the cost by $10 \%$, but the industry charges less the product in natura.

Learning occurs in connection with courses, lectures offered at the headquarters of LPA and visits at area fairs. According to Grohmann et al. (2010, p. 26) "the exchange of information assumes central importance in business to business relationship, in that it raises the level of knowledge of the group, functioning as an internal benchmarking and increasing the chances of a higher learning among members" [12].

What is clear is that learning and innovation are very important for the survival of LPA, needing a little more involvement of associates to bring to them, more experiences, new ideas, information and innovations that promote the growth of its members.

\section{Conclusion}

This research aimed to identify the competitive gains of the LPA Saffron Mara Rosa.

Based on the results obtained in this study can be said that the LPA Mara Rosa Saffron presented cooperative gains for the associate, the following criteria: economies of scale and market power (market forces and trade relations); Provisions solutions (shared marketing, training and credibility assurance); learning and innovation (collectively and industry spread); the reduction of costs and risks (productivity and shared activities); social relationships (family ties).

This research identified that the main weaknesses found in LPA Saffron Mara Rosa were: labor, technology for growing and harvesting of saffron, land lease, motivation, documentation, reliability, price and innovation.

The strengths identified in LPA Saffron Mara Rosa were: trade, favorable land, market, and credit cooperative.

The observations made on site in LPA studied, there was a certain distance, ie, there is no strong relational ties between those involved in LPA, such as the government, associates, business partners, society and public and private entities. In addition, actions were observed with low effectiveness and implementation caused by lack of confidence, not sharing ideas, individualism, lack of commitment, internal layout, lack of human resources and predatory competition, which keeps the joint and strengthening the business arrangement.

As a proposal for improvement, suggests the creation of specific credit lines for execution of innovative actions in participating in the LPA firms, creation of consortium / networks, market access programs, technology training, hand training work and management, quality, productivity and certification of its products, subsidies and tax incentives, macroeconomic improvements policies (interest, taxes, foreign exchange, growth rate), develop dynamic competitive advantages (learning and innovation) constant, in addition to government support for project research universities that focus on product development for MSEs organized in clusters and that its governance is present in all public institutions.

In conclusion, to take place in cooperation gains, if at all, in LPA, you need commitment and unity of its components and support, both private agencies as well as public, to encourage innovation, learning and cooperation, thereby fostering the development of local economies.

To continue this research is suggested: providing further studies involving the participation of other clusters.

\section{References}

[1] ARAÚJO, V. M. Local Productive Arrangements of the Automotive Industry in the State of Goiás, Brazil [manuscript] / Vanessa Marzano Araújo. - 2014. 226 p.: il, figs, tabs. Doctoral Thesis - UFU - MG. 
[2] CASSIOLATO, J., LASTRES, H. The focus on productive and innovative arrangements of local micro and small enterprises. In: LASTRES, H.; CASSIOLATO, J.; MACIEL, M.; (Eds). Small Business: Cooperation and Local Development. Rio de Janeiro: Ed Relum and Damara. 2003.

[3] CAMPOS, R. R, et al. Learning by interaction: small businesses productive and innovative local systems. In: LASTRES, M. H. M.; CASSIOLATO, J. E.; MACIEL, M.L Small Business: cooperation and local development. Relume Dumará Publisher, 2004.

[4] BRITO, J. \& ALBAGLI, S. Glossary arrangements and productive and innovative local systems. REDESIST. Research networks in local production systems. Rio de Janeiro: 2003.

[5] COSTA, E. J. M. Local productive arrangements, public policy and regional development. Brasilia: More Graphic, 2010.

[6] BALESTRIN, A; VERSCHOORE, JR Enterprise Cooperation Networks: management strategies in the new economy. Porto Alegre: Bookman, 2008.

[7] SANTOS, G. A. G of, DINIZ, E. J and BARBOSA, E. K. Local productive arrangements and regional development. In: National Bank for Economic and Social Development. BNDES seminar on Local Productive Arrangements. Belo Horizonte, 2004. v. 11 n. 22 p. 151-179.
[8] MINAYO, M. C. S. The challenge of knowledge: Qualitative research in health. 12th Ed, England: Hucitec-ABRASCO, 2010.

[9] MIGUEL, P. A. C. (ed). Research Methodology in Industrial Engineering and Operations Management. Rio de Janeiro: Elsevier, 2nd ed. 2012.

[10] RG-LPA. Goiana network Support for Local Productive Arrangements. Development Plan: LPA Saffron Rose and Mara Region. Sectec. Goiânia. 2007.

[11] CASTRO, R. R. (Coord.) et al. Mapping and Analysis of Policies for Local Production Arrangements in the South, Southeast and Midwest of Brazil. Final report. Summary of Results, Conclusions and Recommendations - Goias Rio de Janeiro. 2010

[12] GROHMANN, M. Z, et al. Small and medium-sized enterprises cooperation networks: Competitive factors applied in a network of real estate. Management \& Regionality vol.26 No. 78. RS, 2010. pp 18-35. 